\title{
Preventing knee injuries in adolescent female football players - design of a cluster randomized controlled trial [NCT00894595] Martin Hägglund ${ }^{* 1}$, Markus Waldén ${ }^{1,2}$ and Isam Atroshi' ${ }^{2,3}$
}

Address: ${ }^{1}$ Department of Medical and Health Sciences, Linköping University, 58183 Linköping, Sweden, ${ }^{2}$ Department of Orthopedics, Hässleholm and Kristianstad Hospitals, Box 351, 28125 Hässleholm, Sweden and 3Department of Clinical Sciences, Lund University, Box 117, 22100 Lund, Sweden

Email: Martin Hägglund* - martin.hagglund@liu.se; Markus Waldén - markus.walden@telia.com; Isam Atroshi - isam.atroshi@skane.se

* Corresponding author

Published: 23 June 2009

BMC Musculoskeletal Disorders 2009, 10:75 doi:10.1186/147/-2474-10-75
Received: 5 June 2009

Accepted: 23 June 2009

This article is available from: http://www.biomedcentral.com/147/-2474/10/75

(c) 2009 Hägglund et al; licensee BioMed Central Ltd.

This is an Open Access article distributed under the terms of the Creative Commons Attribution License (http://creativecommons.org/licenses/by/2.0), which permits unrestricted use, distribution, and reproduction in any medium, provided the original work is properly cited.

\begin{abstract}
Background: Knee injuries in football are common regardless of age, gender or playing level, but adolescent females seem to have the highest risk. The consequences after severe knee injury, for example anterior cruciate ligament $(A C L)$ injury, are well-known, but less is known about knee injury prevention. We have designed a cluster randomized controlled trial (RCT) to evaluate the effect of a warm-up program aimed at preventing acute knee injury in adolescent female football.

Methods: In this cluster randomized trial 516 teams (309 clusters) in eight regional football districts in Sweden with female players aged 13-17 years were randomized into an intervention group (260 teams) or a control group (256 teams). The teams in the intervention group were instructed to do a structured warm-up program at two training sessions per week throughout the 2009 competitive season (April to October) and those in the control group were informed to train and play as usual. Sixty-eight sports physical therapists are assigned to the clubs to assist both groups in data collection and to examine the players' acute knee injuries during the study period. Three different forms are used in the trial: (I) baseline player data form collected at the start of the trial, (2) computer-based registration form collected every month, on which one of the coaches/team leaders documents individual player exposure, and (3) injury report form on which the study therapists report acute knee injuries resulting in time loss from training or match play. The primary outcome is the incidence of $A C L$ injury and the secondary outcomes are the incidence of any acute knee injury (except contusion) and incidence of severe knee injury (defined as injury resulting in absence of more than 4 weeks). Outcome measures are assessed after the end of the 2009 season.

Discussion: Prevention of knee injury is beneficial for players, clubs, insurance companies, and society. If the warm-up program is proven to be effective in reducing the incidence of knee injury, it can have a major impact by reducing the future knee injury burden in female football as well as the negative long-term disabilities associated with knee injury.
\end{abstract}

Trial registration: NCT00894595 


\section{Background}

Football is the most popular sport worldwide. Unfortunately, football-related knee injuries are common and constitute a serious problem regardless of the playing level. The injury that draws most attention is the anterior cruciate ligament (ACL) injury. This injury usually causes long absence from football and may even force some players to give up their career [1]. ACL injury is also associated with an increased risk of new knee injury $[2,3]$, as well as long-term medical disability related to osteoarthritis $[4,5]$.

There are, however, only few investigated risk factors for ACL injury in football. First, many studies have shown a higher incidence among female than male players [6]. Second, low age is a risk factor for female players and the risk seems to be highest during the late pubertal or first postpubertal years [7]. Third, match play is associated with a considerably higher risk of ACL injury compared to training [8-11]. Several other potential risk factors, for example anatomical and biomechanical factors, have repeatedly been discussed in the literature, but lack scientific evidence [12]. Recently, it has been speculated that a high match frequency as well as match play at senior level could be a risk factor among female adolescent football players [1], but evidence for such a relationship is currently lacking.

Several studies have been conducted with the aim of preventing serious knee injuries and/or ACL injuries in female football [13-20]. However, only two of these studies have shown that the risk of ACL injury can be reduced using a comprehensive warm-up program $[13,16]$. In one study, the injury risk may actually have been increased in the group allocated to balance board training [20]. Unfortunately, many of the studies have serious methodological limitations, such as having few included participants or high drop-out rates resulting in low statistical power $[14,15,17,20]$. Furthermore, the studies commonly do not account for true exposure (playing time) resulting in a less accurate estimation of the actual injury risk [13-17]. Finally, another well-known problem is a poor compliance with the intervention [19], probably due to very ambitious programs taking too much time from the ordinary football training.

A structured warm-up program specifically developed for youth and adolescent team sports has been recently introduced in Sweden (Knäkontroll, SISU Idrottsböcker ${ }^{\circ}$, Sweden, 2005). This commercially available program contains six exercises focusing on neuromuscular knee control and core stability and is intended to be administrated by coaches. The effectiveness of the program in reducing the incidence of knee injury has, however, not been evaluated. The purpose of the present study is to conduct a cluster randomized controlled trial (RCT) evaluat- ing the effectiveness of the program in adolescent female football players. Our hypothesis is that the structured warm-up program reduces the incidence of ACL injury as well as the incidence of any acute knee injury (except contusion) and severe knee injury (defined as injury resulting in absence of more than 4 weeks).

\section{Methods \\ Study design and definitions}

The study is a two-armed RCT designed in accordance with the CONSORT statement guidelines [21]. The definitions follow the international guidelines for football injury research published recently (Table 1$)[22,23]$. The study was registered in ClinicalTrials.gov at the start of the study http://clinicaltrials.gov.

\section{Club recruitment}

Eight regional districts of the Swedish Football Association (FA) located in the south and middle of Sweden were invited to participate in the study being carried out during the 2009 campaign. Leading officials from the selected districts were contacted by telephone in August 2008 and all agreed to support club recruitment to the study. Only female players aged 13-17 years (born 1992 to 1996) were eligible for inclusion in the study. Clubs were informed about the trial by advertisement on the websites of each regional district and through invitational e-mails and letters in December 2008. Club enrolment registries for the 2009 season were obtained for the U-14 to U-18 series from all districts in February 2009 and the coaches of all eligible teams were contacted by the authors ( $\mathrm{MH}$ and MW). Some coaches of teams belonging to the senior league systems responded to the invitation and these teams were included if the squads consisted mainly of adolescent girls in the age groups eligible for study. Teams that did not respond to the invitation or declined participation, those that had less than two scheduled training sessions per week, and those already using the structured warm-up program or a similar preventive program were not included in the study.

\section{Randomization}

All clubs (516 teams) that agreed to participate were randomized into an intervention or control group (Figure 1). All teams from the same club were assigned to the same group. The computer-generated cluster randomization was performed by one of the authors (IA) who is not involved in the intervention.

\section{Study therapist education}

Physical therapists were recruited to the study to educate the coaches and assist the clubs with data collection. The study therapists were members of the Swedish Society of Football Physical Therapists or the Swedish Society of Sports Medicine. A 3-hour educational meeting for the 
Table I: Operational definitions used in the study.

\begin{tabular}{ll}
\hline Term & Definition \\
\hline $\begin{array}{l}\text { Activity } \\
\text { Training session }\end{array}$ & Scheduled training session or match carried out with the player's own or another team. \\
Match & Team training that involved physical activity under the supervision of the team coach. \\
Acute knee injury & Friendly or competitive match against another team. \\
& Injury to the knee joint with sudden onset and known cause, excluding contusions, leading to a player being unable to \\
fully participate in future training or match play (i.e. time loss injury). \\
Meniscus lesion & Acute injury to ligament or joint capsule. \\
Cartilage lesion & Acute injury to the medial or lateral meniscus (verified by MRI or surgery). \\
Bone marrow lesion & Acute injury to the articular cartilage (verified by MRI or surgery). \\
Fracture & Acute injury to the bone marrow including occult fractures (verified by MRI). \\
Dislocation & Acute injury to the bone (verified by plain X-ray). \\
Re-injury & Acute partial or complete dislocation of the patellofemoral joint or the knee joint. \\
Early recurrent injury & Injury of the same type and to the same site as a previous injury the player had sustained in her career. \\
Late recurrent injury & Re-injury within two months of return to full participation after the index injury. \\
Injury severity & Re-injury more than two months after return to full participation from the index injury. \\
Minimal injury & Time elapsed from injury to full participation (days). \\
Mild injury & Injury causing I-3 days absence from training and match play. \\
Moderate injury & Injury causing 4-7 days absence from training and match play. \\
Severe injury & Injury causing 8-28 days absence from training and match play. \\
Injury mechanism & Injury causing >28 days absence from training and match play. \\
Contact injury & Injury resulting from contact with another player or object, but not the surface. \\
Non-contact injury & Injury not resulting from contact with another player or object. \\
Injury incidence & Number of injuries per I000 player-hours. \\
\hline
\end{tabular}

MRI: Magnetic Resonance Imaging

study therapists was held by the authors ( $\mathrm{MH}$ and $\mathrm{MW}$ ) in November 2008. The meeting consisted of a presentation of the theoretical background to knee injury epidemiology in female adolescents and description of the study design followed by a practical education in the program given by an experienced supervisor. The participating therapists also received a specific manual describing the study methodology in detail as well as the tasks associated with the study. A few therapists, who were not yet recruited at the time of the educational meeting, received the same information on a later occasion before the start of the study. A total of 68 therapists accepted to participate in the trial.

\section{Coach education}

All randomized teams were invited to regional instructional meetings held by the authors ( $\mathrm{MH}$ and $\mathrm{MW}$ ) before the start of the trial. In the intervention group, one coach or team leader from each club together with one player ("team captain") took part in a 3-hour meeting. Knee injury epidemiology in female adolescents, the study design and the data collection procedures were presented. This theoretical session was followed by a practical education in the structured warm-up program given by the study therapists. Each coach/team leader received a CD and a leaflet describing the warm-up exercises. In addition, they received a study manual describing the methodology, operational definitions and data collection procedures. The manual contains several examples of how to fill in the study forms. Coaches or team leaders that could not attend the educational meetings were sent the same theoretical session as a slide show presentation and received the practical education by their study therapists before the start of the trial.

Coaches of clubs assigned to the control group received a one-hour lecture about study background and methodology as well as the study manual but were informed to train and play as usual throughout the season. They were also informed that if the study shows that the warm-up program is successful in preventing knee injuries they will be offered the same practical education of the exercises before the start of the 2010 season.

\section{Intervention}

The structured warm-up program (Knäkontroll, SISU Idrottsböcker ${ }^{\circ}$, Sweden, 2005) was developed for youth and adolescent team sports and is intended to be administrated by coaches. It was designed by experienced physical therapists involved in the medical organisations of the Swedish Football Association (FA) in collaboration with the Swedish Handball Federation, the Swedish Basketball Federation and the Swedish Floorball Federation. It contains six exercises focusing on neuromuscular knee control and core stability: (1) one-legged knee squat, (2) pelvic lift, (3) two-legged knee squat, (4) the bench, (5) the lunge, and (6) jump/landing (Table 2). Each exercise is subdivided into four steps of progressing difficulty (A to 


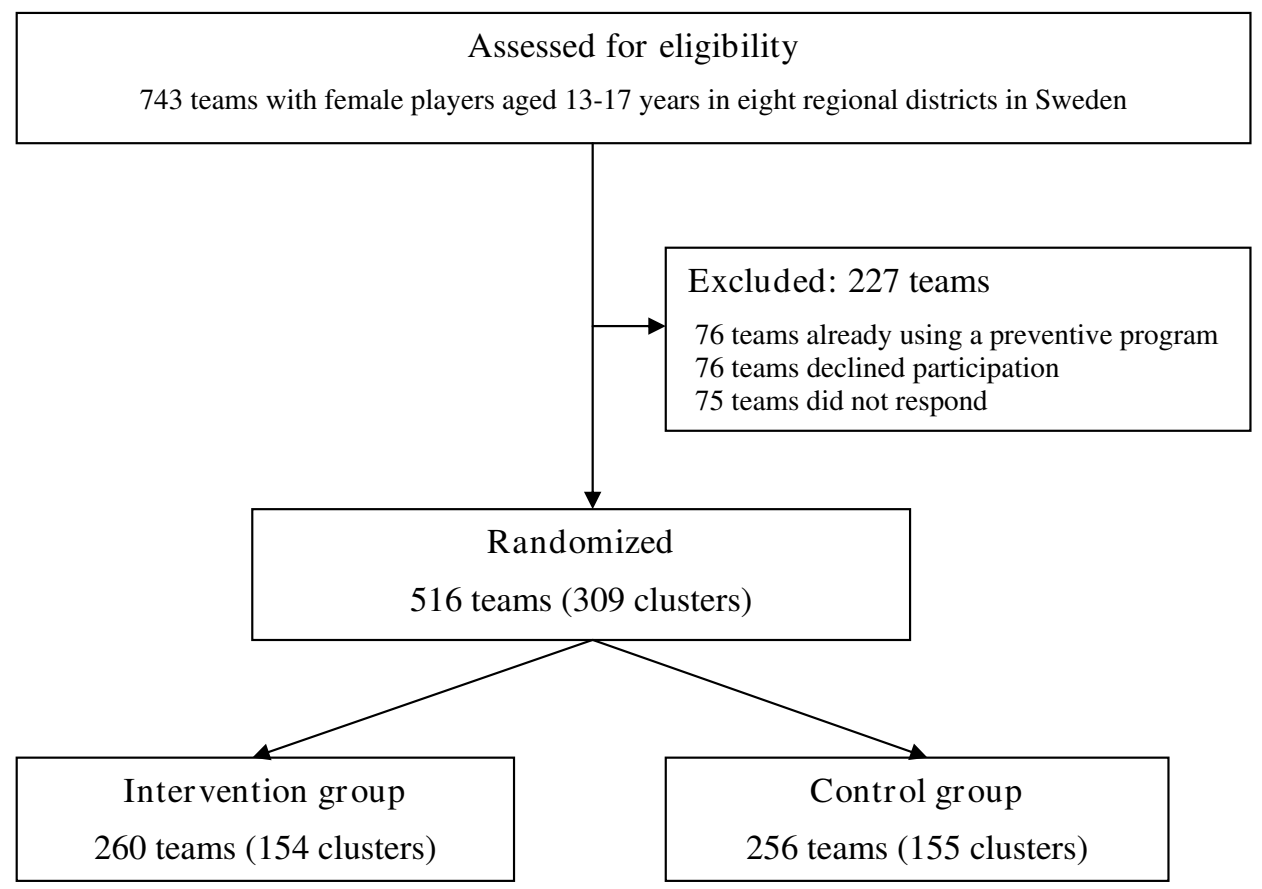

Figure I

Flow of teams and clusters (all teams from the same club are assigned to the same cluster) through the trial.

D) and each association/federation adjusted the progression of the exercises to be sport-specific. In addition, a pair-exercise was developed for intermittent use with the aim of making the training more varying and fun (Table 2 ). The structured warm-up program is commercially available on a CD with a corresponding leaflet describing the execution and purpose of each exercise.

The clubs assigned to the intervention group were instructed to perform the exercises during the warm-up at two training sessions per week throughout the entire 2009 competitive season. The exercises are preceded by 5 minutes of low-intensity running and take about 10-15 minutes to complete after familiarization. Coaches and players are encouraged to watch each other closely and give feedback about the execution of exercises. All players start on the first level of difficulty (A) and the coach clears each player's progress to the next level when she performs the exercise with good control, mainly focusing on core stability and proper knee alignment.

\section{Data collection}

Data is collected during the competitive season from April until the end of the season in October (approximately 7 months). At the start of the study, a baseline form containing information about name, social security number, stature, body mass, menarche, family history of ACL injury, and the player's previous knee injuries and any current complaints is filled in by the player and parents/guardians. During the season, individual player exposure for each training session and match is reported by a coach or team leader on a computer-based registration form that is e-mailed to the research centre monthly. If a player has additional exposures outside the team, such as training or match play with a national team or with a senior team of the club, these are also registered on the exposure form. If a player sustains an acute knee injury during football training or match, the coach contacts the study therapist assigned to the club for evaluation of the injury. All acute knee injuries, except contusions, resulting in absence from play (time loss) are documented soon after the event by the study therapist on a standardized injury report form. If a severe knee injury is suspected, the player can be either advised to visit the nearest emergency department or referred to a study physician involved in the study. One physician experienced in diagnosing knee injuries is assigned to each regional district to assist the study therapists in the evaluation of severe knee injury. All players sustaining possible first-time ACL injuries (based on history and/or clinical examination) will be routinely examined with magnetic resonance imaging (MRI) by the study physicians to verify the diagnosis and to evaluate associated injuries. Suspected re-ruptures or secondary intraarticular injuries in knees with a previously reconstructed ACL will be assessed individually according to best practice. Injuries occurring at school, in other sports or during 
Table 2: The structured warm-up program used in the intervention group

\begin{tabular}{|c|c|c|}
\hline Exercise & Instructions & Repetitions or duration* \\
\hline I. One-legged knee squat & $\begin{array}{l}\text { Slow movement with a smooth turn. Keep the pelvis in a horizontal position. Non- } \\
\text { supporting foot held in front of the body with slightly flexed hip and knee. }\end{array}$ & \\
\hline Level A & Hands on the hips. & $3 \times 8-15$ \\
\hline Level B & Hold a ball over the head with straight arms. & $3 \times 8-15$ \\
\hline Level C & $\begin{array}{l}\text { Hands on the hips. Mark with the non-supporting foot just above the ground at the 12- } \\
02-04-06 \text { o'clock positions. }\end{array}$ & $3 \times 5$ \\
\hline Level D & $\begin{array}{l}\text { Bend down while holding a ball and let the ball touch the ground outside the supporting } \\
\text { foot. Make a diagonal movement upwards and raise the ball over the head with straight } \\
\text { arms on the contralateral side. }\end{array}$ & $3 \times 8-15$ \\
\hline Pair-exercise & $\begin{array}{l}\text { Teammate stands slightly oblique in front of you. Hands on the hips and press a ball } \\
\text { between the lateral sides of the feet of the non-supporting legs. }\end{array}$ & $3 \times 5-10$ \\
\hline 2. Pelvic lift & Supine position. Lift the pelvis from the ground while keeping the back straight. & \\
\hline Level A & Both feet on the ground and hands across the chest. & $3 \times 8-15$ \\
\hline Level B & $\begin{array}{l}\text { One foot on the ground and the contralateral leg flexed in the hip and knee } \\
\text { approximately } 90 \text { degrees with both hands on the knee. }\end{array}$ & $3 \times 8-15$ \\
\hline Level C & $\begin{array}{l}\text { One foot on a football and the contralateral leg flexed in the hip and knee approximately } \\
90 \text { degrees with the arms on the ground alongside the body for support. }\end{array}$ & $3 \times 8-15$ \\
\hline Level D & $\begin{array}{l}\text { One foot on the ground and the other in the air. Keep the upper arms on the ground for } \\
\text { support with the elbows flexed } 90 \text { degrees. Push away the supporting foot and land on } \\
\text { the contralateral foot. }\end{array}$ & $3 \times 8-15$ \\
\hline Pair-exercise & $\begin{array}{l}\text { Teammate stands with flexed knees and supports the heel of one of your feet in her } \\
\text { hands. Hands across the chest and lift the pelvis. }\end{array}$ & $3 \times 8-15$ \\
\hline 3. Two-legged knee squat & $\begin{array}{l}\text { Slow movement with a smooth turn. Keep the back in a straight position. Feet shoulder- } \\
\text { wide apart with the soles in contact with the ground at all times during the squat. }\end{array}$ & \\
\hline Level A & Hold a ball in front of the body with straight arms. & $3 \times 8-15$ \\
\hline Level B & Hands on the hips. & $3 \times 8-15$ \\
\hline Level C & Hold a ball over the head with straight arms. & $3 \times 8-15$ \\
\hline Level D & $\begin{array}{l}\text { Same as Level C, but continue the movement and rise up on the toes after returning to } \\
\text { the starting position. Stay briefly in that position with good control. }\end{array}$ & $3 \times 8-15$ \\
\hline Pair-exercise & $\begin{array}{l}\text { Teammate stands next to you approximately I meter away, face opposite directions. } \\
\text { Hold a ball between you with one hand and the other hand on the hip. Apply slight } \\
\text { pressure on the ball while performing the knee squat. }\end{array}$ & $3 \times 8-15$ \\
\hline 4. The bench & Lift the body and keep it in a straight line. & \\
\hline Level A & $\begin{array}{l}\text { Prone position. Support on the knees and on the lower arms with the elbows kept under } \\
\text { the shoulders. }\end{array}$ & $15-30$ seconds \\
\hline Level B & Same as Level $A$ but with support on the tip of the feet. & $15-30$ seconds \\
\hline Level C & $\begin{array}{l}\text { Same as Level B, but move the foot to the side and back to the starting position. } \\
\text { Alternate sides. }\end{array}$ & $15-30$ seconds \\
\hline Level D & $\begin{array}{l}\text { Lie sideways with support on the foot and the lower arm with the elbow kept under the } \\
\text { shoulder and the other hand on the hip. Lift the hip off the ground and stay briefly in that } \\
\text { position with good control before slowly returning to the starting position. }\end{array}$ & $3 \times 5-10$ \\
\hline Pair-exercise & $\begin{array}{l}\text { Teammate stands behind you and holds your feet or lower legs. Lift the body and walk } \\
\text { forward by using the hands on the ground. }\end{array}$ & $15-30$ seconds \\
\hline 5. The lunge & Take a step with a marked knee lift and a soft landing. & \\
\hline Level A & Hands on the hips. Move forward with each step. & $3 \times 8-15$ \\
\hline Level B & $\begin{array}{l}\text { Hold a ball in front of the body with straight arms. Rotate the upper body while stepping } \\
\text { forward and position the ball laterally of the front leg. Move forward with each step and } \\
\text { alternate sides. }\end{array}$ & $3 \times 8-15$ \\
\hline Level C & $\begin{array}{l}\text { Hold a ball over the head with straight arms. Perform a forward lunge and push back } \\
\text { with the front leg and return to the starting position. }\end{array}$ & $3 \times 8-15$ \\
\hline Level D & $\begin{array}{l}\text { Hold a ball in front of the body with straight arms. Perform a sideway lunge and return } \\
\text { to the starting position. }\end{array}$ & $3 \times 8-15$ \\
\hline Pair-exercise & $\begin{array}{l}\text { Teammate stands in front of you 5-10 meters away. Perform a forward lunge while } \\
\text { making a throw-in with a ball. }\end{array}$ & $3 \times 8-15$ \\
\hline 6. Jump/landing & Make a jump with a soft landing. Stay briefly in the landing position. & \\
\hline Level A & $\begin{array}{l}\text { Stand on one leg with the knee slightly bent and hands on the hips. Make a short forward } \\
\text { jump and land on the same foot. Jump backwards to the starting position. }\end{array}$ & $3 \times 8-15$ \\
\hline Level B & $\begin{array}{l}\text { Stand on two legs shoulder-wide apart with the hands on the back. Make a sideways } \\
\text { jump and land on one foot. Alternate sides. }\end{array}$ & $3 \times 8-15$ \\
\hline Level C & $\begin{array}{l}\text { Take a few quick steps on the same spot and make a short jump straight forward landing } \\
\text { on one foot. }\end{array}$ & $3 \times 5$ \\
\hline
\end{tabular}


Table 2: The structured warm-up program used in the intervention group (Continued)

\begin{tabular}{lll}
\hline Level D & Same as level C, but change direction and jump to one side (90 degrees turn). Alternate & $3 \times 5$ \\
& sides. & \\
Pair-exercise & $\begin{array}{l}\text { Teammate stands in front of you approximately } 5 \text { meters away. Make a two-legged jump } \\
\text { while heading a football and land on two legs. }\end{array}$ & $3 \times 8-15$ \\
&
\end{tabular}

Exercises I, 3, 5 and 6: Focus on knee over foot position

Exercises 2, 3, 4 and 5: Ensure abdominal and gluteal muscle contraction for increased lower back support

$*$ Number of repetitions unless otherwise specified.

leisure time are not registered. Injuries are followed until full return to play or until 1 year post-injury.

\section{Compliance}

At the start of the study, coaches in the intervention group deliver a preliminary training schedule specifying the two weekly sessions where the structured warm-up program is planned to be carried out. Any subsequent changes in the schedule need to be reported to the study therapist. The coach documents on the exposure form if the program has been carried out as scheduled. The study therapists will make unannounced visits to their teams in the intervention group twice during the study period (once during the spring season and once during the autumn season) to monitor compliance to the program. Study therapists are encouraged to contact teams with low compliance (fewer than 6 prevention sessions over a 4 -week period) to motivate them and increase their compliance.

\section{Ethics}

The study was approved by the Regional Ethical Review Board in Linköping (\# M197-08). All players are verbally informed about the study by their coaches before the start of the study and also receive information to read together with their parents/guardians. Participation in the study is voluntary and all players sign written informed consent together with their parents/guardians according to the Declaration of Helsinki. None of the authors are involved in diagnosis or treatment of player injuries.

\section{Sample size}

The sample size was based on previous data showing an average annual/seasonal incidence of ACL injury among female adolescent football players of $1.15 \%$ as reported in one prospective study [24] or in the control groups of previous knee injury prevention studies (Table 3) $[14-17,19]$. With a power of $80 \%$, significance level of $5 \%$, and an estimated risk reduction of $50 \%$ in the intervention group, randomization of approximately 4000 players to each group would be required [25].

\section{Statistical analysis}

The incidence will be calculated as number of injuries per 1000 playing hours. The primary outcome of the study is the incidence of ACL injury. The secondary outcomes are the incidence of any acute knee injury (except contusion) and the incidence of severe knee injury (defined as injury resulting in absence of more than 4 weeks). All outcomes will be evaluated according to the mechanism of injury (contact or non-contact). The exposure and injuries for a team in the intervention group is calculated from the first interventional session performed during the season (matched with the same date to a team in the control group). All analyses will be performed both according to the intention-to-treat principle and according to per protocol. The analyses will be performed with group identity concealed. Clustering will be accounted for in the analyses and the intracluster correlation coefficient will be computed. A Cox regression model with cluster as a random effect will be performed as well as a multilevel mixed model analysis based on Poisson regression. The relative risk reduction (RRR) is calculated using the rate in the control group divided by the rate in the intervention group and will be reported as a ratio with $95 \%$ confidence interval. Covariates in the analyses will include age, menarche, previous knee injury, match frequency and

Table 3: Annual/seasonal incidence of ACL injury in prospective cohort or controlled intervention studies in adolescent female football used for the sample size calculation.

\begin{tabular}{|c|c|c|c|c|}
\hline Study & Population & Study design & $\begin{array}{l}\text { Number of players in the } \\
\text { control group }\end{array}$ & $\begin{array}{l}\text { Number of players with } \\
\text { ACL injury (\%) }\end{array}$ \\
\hline Hewett et al., I999 [15] & High school & Controlled trial & 193 & $2(1.04 \%)$ \\
\hline Heidt et al., 2000 [14] & Age $14-18$ years & Randomized controlled trial & 258 & $8(3.10 \%)$ \\
\hline $\begin{array}{l}\text { Powell \& Barber-Foss, } 2000 \\
\text { [24] }\end{array}$ & High school & Prospective cohort study & 6642 & $33(0.50 \%)$ \\
\hline Mandelbaum et al., 2005 [16] & Age $14-18$ years & Controlled trial & 3818 & 67 (I.76\%) \\
\hline Pfeiffer et al. 2006 [I7] & High school & Controlled trial & 189 & 0 \\
\hline Steffen et al., 2008 [19] & Age $13-17$ years & Randomized controlled trial & 947 & $5(0.53 \%)$ \\
\hline
\end{tabular}


match play with other teams than the player's own. The absolute risk reduction (ARR) is calculated using the rate in the control group minus the rate in the intervention group. The number needed to treat (NNT) will be calculated based on the ARR. All statistical tests will be 2-sided and a significance level of $<0.05$ will be used.

\section{Discussion}

Knee injuries in football are common regardless of age, gender or playing level, but adolescent females seem to have the highest risk. Prevention of knee injury would be beneficial for players, clubs, insurance companies, and society. This cluster randomized controlled trial is designed to evaluate the effect of a commercially available structured warm-up program in adolescent female football. The strengths of our study include the large study sample compared to most of previous research in the field [13-15,17-20] and the use of a recently validated methodology $[22,23]$. In addition, the documentation of background information and individual player exposure will allow us to evaluate the risk of knee injury and control for possible interaction or confounding factors.

One limitation of the present trial is that it was not possible to perform a power calculation for a cluster RCT from exposure-based incidence rates of ACL injury, since valid data is lacking in the literature. Consequently, we cannot know for sure that the study sample is large enough. Another limitation is that the sports physical therapists supporting the teams and evaluating knee injuries are not blinded to group allocation. We decided to favour a professional evaluation of players' acute knee injuries by the physical therapists and it was not possible to recruit additional therapists specifically to assist teams with data collection and to instruct and monitor compliance to the preventive program. Due to the nature of the intervention, blinding of players or coaches to group allocation is not possible. Study physicians evaluating severe knee injuries are, however, blinded to group allocation.

\section{Competing interests}

The authors declare that they have no competing interests.

\section{Authors' contributions}

$\mathrm{MH}$ and MW designed the study and are the principle researchers responsible for recruitment and data collection. IA contributed to the design of the study and performed the randomization. $\mathrm{MH}$ and $\mathrm{MW}$ are study guarantors. All authors contributed to the writing of the protocol and approved the final manuscript.

\section{Acknowledgements}

The authors thank Anneli Gustafsson, project assistant at the Swedish FA, Annica Näsmark, RPT, and member of the Medical Committee of the Swedish FA, and Per Renström, MD, PhD and head physician of the Swedish FA for their support as well as all coaches and players participating in the study.

\section{Funding}

The study was supported mainly by grants from the Swedish FA and Folksam Insurance Company. Grants were also received from the Swedish National Centre for Research in Sports.

\section{References}

I. Söderman K, Pietilä T, Alfredson H, Werner S: Anterior cruciate ligament injuries in young females playing soccer at senior levels. Scand J Med Sci Sports 2002, I 2:65-68.

2. Faude O, Junge A, Kindermann W, Dvorak J: Risk factors for injuries in elite female soccer players. $\mathrm{Br} J$ Sports Med 2006, 40:785-790.

3. Waldén $M$, Hägglund $M$, Ekstrand J: High risk of new knee injury in elite footballers with previous anterior cruciate ligament injury. BrJ Sports Med 2006, 40:158-162.

4. Lohmander LS, Östenberg, Englund M, Roos H: High prevalence of knee osteoarthritis, pain, and functional limitations in female soccer players twelve years after anterior cruciate ligament injury. Arthritis Rheum 2004, 50:3 I45-3 I 52.

5. von Porat A, Roos EM, Roos H: High prevalence of osteoarthritis 14 years after an anterior cruciate ligament tear in male soccer players: a study of radiographic and patient relevant outcomes. Ann Rheum Dis 2004, 63:269-273.

6. Prodromos CC, Han Y, Rogowski J, Joyce B, Shi K: A meta-analysis of the incidence of anterior cruciate ligament tears as a function of gender, sport, and a knee injury-reduction regimen. Arthroscopy 2007, 23: I320-I325.

7. Shea KG, Pfeiffer R, Wang JH, Curtin M, Apel PJ: Anterior cruciate ligament injury in pediatric and adolescent soccer players: an analysis of insurance data. J Pediatr Orthop 2004, 24:623-628.

8. Faude $O$, Junge A, Kindermann W, Dvorak J: Injuries in female soccer players: a prospective study in the German national league. Am J Sports Med 2005, 33: 1694-I700.

9. Fuller CW, Dick RW, Corlette J, Schmalz R: Comparison of the incidence, nature and cause of injuries sustained on grass and new generation artificial turf by male and female football players. Part I: match injuries. Br J Sports Med 2007, 4 I (SuppI I):20-26.

10. Fuller CW, Dick RW, Corlette J, Schmalz R: Comparison of the incidence, nature and cause of injuries sustained on grass and new generation artificial turf by male and female football players. Part 2: training injuries. Br J Sports Med 2007, 4 I (Suppl I):27-32.

II. Giza E, Mithöfer K, Farrell L, Zarins B, Gill T: Injuries in women's professional soccer. Br J Sports Med 2005, 39:2I 2-2 I6.

12. Hewett TE, Myer GD, Ford KR: Anterior cruciate ligament injuries in female athletes: Part $I$, mechanisms and risk factors. Am J Sports Med 2006, 34:299-3II.

13. Gilchrist J, Mandelbaum BR, Melancon H, Ryan GW, Silvers HJ, Griffin LY, Watanabe DS, Dick RW, Dvorak J: A randomized controlled trial to prevent noncontact anterior cruciate ligament injury in female collegiate soccer players. Am J Sports Med 2008, 36:1476-1483.

14. Heidt RS Jr, Sweeterman LM, Carlonas RL, Traub JA, Tekulve FX: Avoidance of soccer injuries with preseason conditioning. Am J Sports Med 2000, 28:659-662.

15. Hewett TE, Lindenfeld TN, Riccobene JV, Noyes FR: The effect of neuromuscular training on the incidence of knee injury in female athletes. Am J Sports Med 1999, 27:699-705.

16. Mandelbaum BR, Silvers HS, Watanabe DS, Knarr JF, Thomas SD, Griffin LY, Kirkendall DT, Garrett W Jr: Effectiveness of a neuromuscular and proprioceptive training program in preventing anterior cruciate ligament injuries in female athletes. $\mathrm{Am}$ J Sports Med 2005, 33:1003-1010.

17. Pfeiffer RP, Shea KG, Roberts D, Grandstrand S, Bond L: Lack of effect of a knee ligament injury prevention program on the incidence of noncontact anterior cruciate ligament injury. JBJS 2006, 88-A: I 769-I774.

18. Soligard T, Myklebust G, Steffen K, Holme I, Silvers H, Bizzini M, Junge A, Dvorak J, Bahr R, Andersen TE: A comprehensive warm-up programme to prevent injuries in female youth football - a cluster randomised controlled trial. BMJ 2008, 337:a2469. 
19. Steffen K, Myklebust G, Olsen OE, Holme I, Bahr R: Preventing injuries in female youth football - a cluster-randomised controlled trial. Scand J Med Sci Sports 2008, 18:605-6I4.

20. Söderman K, Werner S, Pietelä T, Engström B, Alfredson H: Balance board training: prevention of traumatic injuries of the lower extremities in female soccer players? A prospective randomized intervention study. Knee Surg, Sports Traumatol, Arthrosc 2000, 8:356-363.

21. Campbell MK, Elbourne DR, Altman DG: CONSORT statement: extension to cluster randomised trials. $B M J$ 2004, 328:702-708.

22. Fuller CW, Ekstrand J, Junge A, Andersen TE, Bahr R, Dvorak J, Hägglund $\mathrm{M}$, McCrory $\mathrm{P}$, Meeuwisse $\mathrm{WH}$ : Consensus statement on injury definitions and data collection procedures in studies of football (soccer) injuries. BrJ Sports Med 2006, 40: 193-20I. Scand J Med Sci Sports 2006, 16:83-92, Clin J Sport Med 2006, 16:97-106

23. Hägglund M, Waldén M, Bahr R, Ekstrand J: Methods for epidemiological studies of injuries to professional football players developing the UEFA model. Br J Sports Med 2005, 39:340-346.

24. Powell JW, Barber-Foss KD: Sex-related injury patterns among selected high school sports. Am J Sports Med 2000, 28:385-39I.

25. Kirkwood BR: Essentials of medical statistics Oxford: Blackwell Scientific Publications; 1988.

\section{Pre-publication history}

The pre-publication history for this paper can be accessed here:

http://www.biomedcentral.com/1471-2474/10/75/pre pub

Publish with Bio Med Central and every scientist can read your work free of charge

"BioMed Central will be the most significant development for disseminating the results of biomedical research in our lifetime. "

Sir Paul Nurse, Cancer Research UK

Your research papers will be:

- available free of charge to the entire biomedical community

- peer reviewed and published immediately upon acceptance

- cited in PubMed and archived on PubMed Central

- yours - you keep the copyright 